OPEN ACCESS

Edited by:

Jiangong Wei,

Guangzhou Marine Geological Survey,

China

Reviewed by:

Chao Li,

Tongji University, China

Yancheng Zhang,

Sun Yat-sen University, China

*Correspondence:

Bangqi Hu

bangqihu@gmail.com

Specialty section: This article was submitted to

Geochemistry,

a section of the journal

Frontiers in Earth Science

Received: 03 September 2021

Accepted: 28 December 2021

Published: 21 January 2022

Citation:

XuF, Hu B, Zhao J, LiuX, Cui R, Ding $X$,

Wang $G$ and Huang J (2022)

Topographic and Climatic Control on Chemical Weathering of Mountainous Riverine Sediments of Hainan Island,

South China Sea.

Front. Earth Sci. 9:770236.

doi: 10.3389/feart.2021.770236

\section{Topographic and Climatic Control on Chemical Weathering of Mountainous Riverine Sediments of Hainan Island, South China Sea}

\author{
Fangjian $\mathrm{Xu}^{1,2}$, Bangqi $\mathrm{Hu}^{2,3 *}$, Jingtao Zhao ${ }^{3}$, Xiting $\mathrm{Liu}^{4}$, Ruyong Cui ${ }^{3}$, Xue Ding ${ }^{3,5}$, \\ Guifeng Wang ${ }^{6}$ and Jianping Huang ${ }^{7}$
}

${ }^{1}$ College of Marine Science, Hainan University, Haikou, China, ${ }^{2}$ Laboratory for Marine Mineral Resources, Qingdao National Laboratory for Marine Science and Technology, Qingdao, China, ${ }^{3}$ Qingdao Institute of Marine Geology, Ministry of Natural Resources, Qingdao, China, ${ }^{4}$ College of Marine Geosciences Key Laboratory of Submarine Geosciences and Prospecting Technology, Ocean University of China, Qingdao, China, ${ }^{5}$ State Key Laboratory of Loess and Quaternary Geology, Institute of Earth Environment, Chinese Academy of Sciences, Xi'an, China, ${ }^{6}$ Marine Geological Institute of Hainan Province, Haikou, China,

${ }^{7}$ School of Geoscience, China University of Petroleum, Qingdao, China

Hainan Island, the largest island in the northwestern South China Sea (SCS), is characterized by many tropical mountainous rivers that flow into the SCS. The geochemistry of these riverine sediments and the factors controlling the weathering intensity are still not well understood. In this study, sedimentary geochemistry has been investigated by using 45 riverine sediments collected from 18 major rivers on Hainan Island. The Hainan riverine sediments are only firstcycle rather than polycyclic sediments, and they faithfully reflect the present weathering intensity. The high and steady values of the Chemical Index of Alteration (CIA) indicate that the riverine sediments at different parts of the Hainan Island have overall undergone intensive chemical weathering. The low values of Weathering Index of Parker (WIP) and high $\alpha_{C a}, \alpha_{K}, \alpha_{S r}$, and $\alpha_{B a}$ values of north Hainan indicate the highest weathering degree, which is mainly influenced by the flat topography. The values of $\alpha_{N a}, \alpha_{K}, \alpha_{S r}$, and $\alpha_{B a}$ of southwest Hainan which are higher than those of east Hainan suggest that the leaching of elements such as $\mathrm{Na}$, $\mathrm{K}, \mathrm{Sr}$, and $\mathrm{Ba}$ is more extreme (i.e., more intensive weathering). These are mainly caused by the different physical denudation due to different summer precipitation. Overall, the Hainan Island is featured by intensive chemical weathering and is classified as a typical transport-limited weathering regime. Therefore, the geochemistry of the riverine sediments of the Hainan Island is different from that of sediments in tectonically active regions (e.g., Taiwan Island).

\section{Keywords: geochemistry, riverine sediment, weathering, Hainan Island, South China Sea}

\section{HIGHLIGHTS}

The Hainan riverine sediments have undergone high weathering conditions.

The highest chemical weathering intensities of sediments in north Hainan are mainly influenced by the flat topography.

Weathering difference between southwest and east Hainan is caused by different summer rainfall conditions due to the orographic effect of the central mountains.

The weathering processes of the sediments in Hainan are typical transport-limited weathering regimes. 


\section{INTRODUCTION}

Rivers are the main passages of land-derived sediments into the sea. The mineralogical and geochemical characteristics of sediments are controlled by lithology, topographic settings, weathering, diagenesis, sedimentary sorting, and recycling in catchments, and can be used to better understand the geochemical cycle, land-ocean interaction, and global change (Gaillardet et al., 1997; Yang et al., 2004; Liu et al., 2007; Li and Yang, 2010; Clift et al., 2014; Li G. et al., 2016; Jian et al., 2020; Xu et al., 2021).

Numerous studies have focused mainly on world-class rivers, such as the Amazon (Gaillardet et al., 1997; Bouchez et al., 2011), Mekong (Egashira et al., 1997), Congo (Dupré et al., 1996; Dinis et al., 2020), Yangtze and Yellow (Yang et al., 2004), and Pearl (Liu et al., 2007) rivers, because they play leading roles in delivering the great mass of water and terrestrial materials to the sea. However, subsequent studies have found that small rivers may have distinctive features in comparison to the major river systems in the world (Milliman and Syvitski, 1992; Milliman and Farnsworth, 2011; Yang and Yin, 2018). Thus, the significance of rivers with small drainage basins has been reconsidered. Recently, the characteristics of sediment geochemistry in small rivers, for example, central Japan (Ohta et al., 2005), western Korea (Xu et al., 2009), southeast China (Zhou et al., 2010; Su et al., 2017; Jian et al., 2020), Taiwan Island (Li et al., 2013; Deng et al., 2019), Malaysia, Sumatra, Borneo (Liu et al., 2012), Luzon, and Philippines (Liu et al., 2009), have aroused wide concern.

Hainan Island is the second largest island in China and the highest island in the northern South China Sea (SCS) and is located at the low latitude tropical area with heavy rainfall but low sediment load ( $4 \mathrm{Mt} / \mathrm{yr}$, million tons per year, Zhang et al., 2013). Clay mineralogy analysis suggested that the weathering status of Hainan is comparable with that of the Pearl River and is inconsistent with that of rivers in Taiwan (Hu et al., 2014). To our knowledge, the geochemistry of the riverine sediments of Hainan Island and the weathering mechanism have not been constrained systemically, which are characterized by different lithological and topographic settings, and along with the tropical East Asian monsoon climate but with different rainfall. In this study, sediment geochemistry has been investigated on 45 riverine sediments collected from 18 major rivers on the Hainan Island. Our objectives are to 1) reveal the characteristic features of sediment geochemistry, 2) establish a geochemistry database for riverine sediments from Hainan Island, and 3)






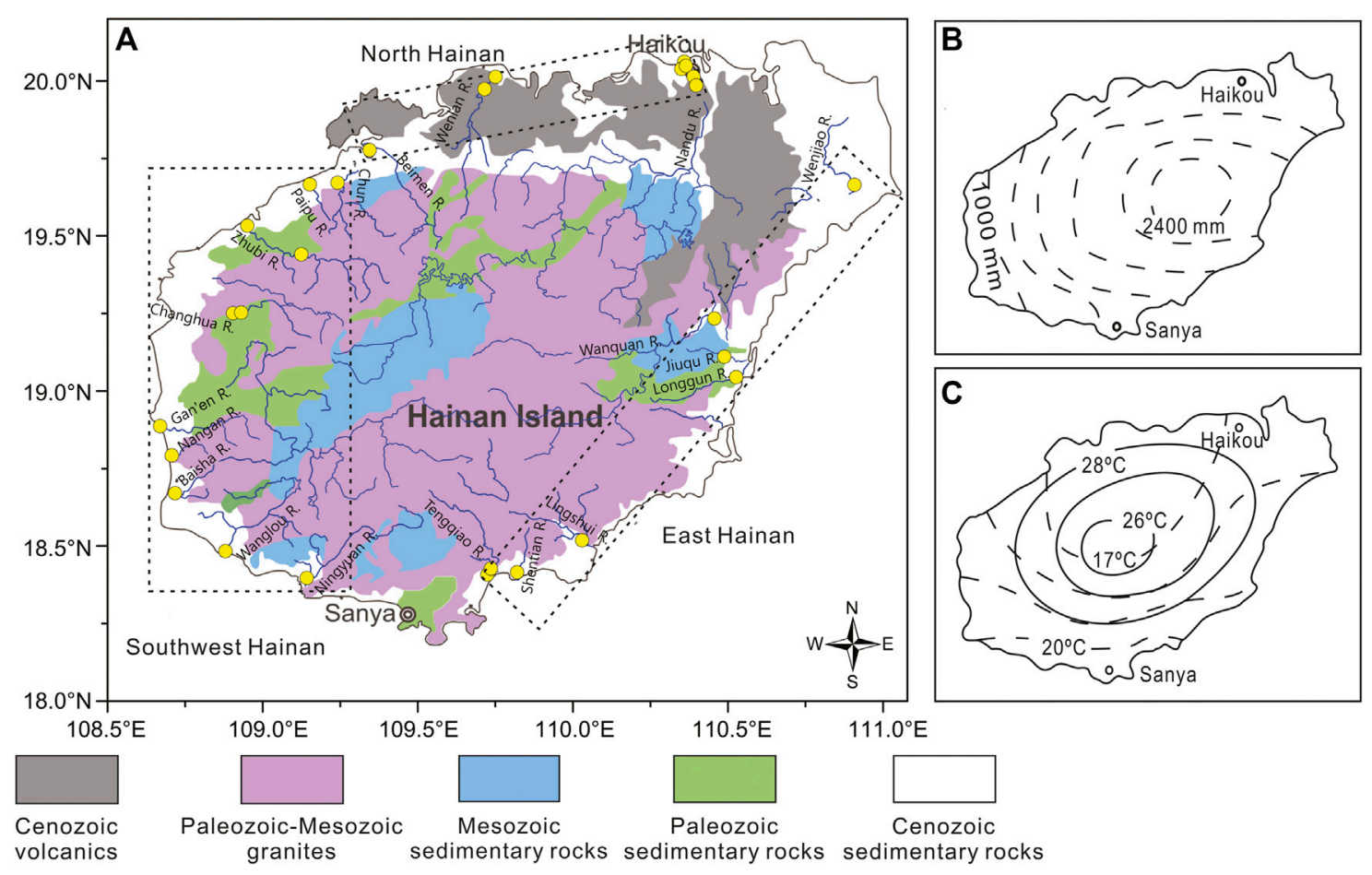

FIGURE 2 | (A) Geological map and the locations of riverine samples on the Hainan Island. Modified from Shi et al. (2011) and Hu et al. (2014). (B) Annual rainfall and (C) temperature of January (dashed lines) and July (solid lines) of the Hainan Island (modified from http://gzdl.cooco.net.cn/testdetail/91943/). The blue lines indicate the river networks. Note that some of the sampling sites are overlapped on the map.

discuss the factors controlling the chemical weathering intensity of sediments in tropical Hainan.

\section{Regional Setting}

Hainan Island is the second largest island $\left(35.4 \times 10^{3} \mathrm{~km}^{2}\right.$, Figure 1A) in China. The Hainan Island is tectonically stable (Metcalfe, 2009) and is characterized by central high mountains surrounding low hills, platforms, and plains in coastal regions (Figure 1B). The high mountains are located south of the central part of the island, accounting for $25.1 \%$ of the island's area. The vast platforms are mainly distributed in the north Hainan (20-50 m above sea level), accounting for about one-third of the total area of the island (http://www.hnszw.org.cn/xiangqing. php? $\mathrm{ID}=54349$, Figure 1B). The main rock types are granitic rocks which are mainly exposed in the southwest and east Hainan, and basalts are distributed predominantly in north Hainan. Sedimentary rocks, including slate, sandstone, limestone, and volcanic clastic, are scattered on the island, while Quaternary sediments have existed mainly in the coastal plain regions (Figure 2A, Shi et al., 2011).

The Hainan Island is located on the northern edge of the tropics and is dominated by a tropical monsoon climate with dense vegetation cover (Committee of Vegetation Map of China, 2007; Zhang et al., 2013). The annual mean rainfall is $\sim 1,500 \mathrm{~mm}$, with $\sim 80 \%$ of it occurring between May and October (http:// www.worldweather.org), especially during the tropical cyclone period (Zhang et al., 2013). A large rainfall difference occurred between different parts of Hainan because of the orographic effect of the central mountains. The annual mean rainfall is distributed in a ring pattern, tending to reduce from more than $2,000 \mathrm{~mm}$ in the east and central Hainan to less than $1,000 \mathrm{~mm}$ in the southwest Hainan (Figure 2B). Fluvial drainage systems are well developed in the region. There are more than 100 rivers with a drainage area of over $100 \mathrm{~km}^{2}$ each. Over the past several decades, the total discharge and the total riverine sediment load from Hainan are $\sim 31 \times 10^{9} \mathrm{~m}^{3} / \mathrm{yr}$ and $\sim 4 \mathrm{Mt} / \mathrm{yr}$ (Zhang et al., 2013), respectively.

The annual mean temperature is $25.4^{\circ} \mathrm{C}$, with a maximum between May and October (http://www.worldweather.org). In July, the isotherm showed concentric circles, increasing from the central mountain to the coastal areas. In January, temperatures were lower in north Hainan, increasing from the northern to the southern areas (Figure 2C). In general, there is a relatively wet and dry climate in east and southwest Hainan.

\section{MATERIALS AND METHODS}

\section{Sampling and Analytical Methods}

A total of 45 riverine samples were collected downstream of estuary sites from 18 rivers on the Hainan Island in 2013 (Figure 2A). According to the lithology and climate conditions, the 18 studied rivers were grouped into three provinces: north Hainan (3 rivers), east Hainan (6 rivers), and 
southwest Hainan (9 rivers). These sediment samples were collected from surface channels or bed deposits. The finegrained fraction $(<63 \mu \mathrm{m}$, after eliminating sand) used for geochemical analysis was wet-sieved from the bulk samples to minimize the grain-size effect (Yang et al., 2002; Bouchez et al., 2011; Li et al., 2013; Guo et al., 2018), then oven-dried, and ground to a powder. The major and trace elements were analyzed using an X-ray fluorescence spectrometer (XRF, Axios PW4400) and Perkin Elmer ELAN DRC II ICP-MS, respectively. The analytical accuracy was determined by analyzing certified reference materials (BCR-2, BHVO-2, GBW07315, and GBW07316). The analytical precision, as verified by replicate analysis, was better than $5 \%$. The clay mineral compositions of the sediments have been reported by Hu et al. (2014).

\section{Calculation of Weathering Indexes}

The Chemical Index of Alteration (CIA) and the Weathering Index of Parker (WIP) have been widely used as proxies for the chemical weathering intensity in drainage basins. The CIA value is used to quantify the chemical weathering degree experienced by sediments, referring to the progressive loss of mobile elements such as $\mathrm{Na}, \mathrm{Ca}$, and K (Nesbitt and Young, 1982). The higher CIA values indicate stronger weathering which could be interpreted as a measure of the conversion extent of feldspars to clays. In contrast, the WIP simply reflects concentrations of $\mathrm{Mg}, \mathrm{Ca}$, $\mathrm{Na}$, and $\mathrm{K}$, and thus, it is considerably affected by quartz dilution and used to evaluate weathering in quartz-rich sediments (Garzanti et al., 2013; Garzanti et al., 2014). Using molecular proportions, the CIA and WIP were calculated as follows:

$$
\begin{gathered}
C I A=100 \times\left(\frac{\mathrm{Al}_{2} \mathrm{O}_{3}}{\mathrm{Al}_{2} \mathrm{O}_{3}+\mathrm{CaO} *+\mathrm{Na}_{2} \mathrm{O}+\mathrm{K}_{2} \mathrm{O}}\right), \\
W I P=100 \times\left(\frac{\mathrm{CaO} *}{0.7}+\frac{2 \mathrm{Na}_{2} \mathrm{O}}{0.35}+\frac{2 \mathrm{~K}_{2} \mathrm{O}}{0.25}+\frac{\mathrm{MgO}}{0.9}\right),
\end{gathered}
$$

where $\mathrm{CaO}^{*}$ represents $\mathrm{CaO}$ associated with the silicate fraction only and is corrected for carbonate and phosphate (apatite). If the mole fraction of $\mathrm{CaO} \leq \mathrm{Na}_{2} \mathrm{O}$, then the value of $\mathrm{CaO}$ was used. If $\mathrm{CaO}>\mathrm{Na}_{2} \mathrm{O}$, then the mole of $\mathrm{CaO}^{*}$ was taken equivalent to $\mathrm{Na}_{2} \mathrm{O}$ (McLennan, 1993).

Weathering intensities can be calculated for each single element $(\mathrm{Ca}, \mathrm{Na}, \mathrm{K}, \mathrm{Sr}$, and $\mathrm{Ba}$ ) mobilized during incongruent weathering of silicates by comparing its concentration to that of an immobile element in samples and the upper continental crust (UCC, i.e., $\alpha$ value, Gaillardet et al., 1999; Garzanti et al., 2013). We calculated the $\alpha$ value with reference to the concentration of an immobile element whose magmatic compatibility is close to that of the mobile element (Gaillardet et al., 1999):

$$
\begin{aligned}
\alpha_{\mathrm{Ca}} & =\frac{[\mathrm{Ti} / \mathrm{Ca}]_{\text {Sample }}}{[\mathrm{Ti} / \mathrm{Ca}]_{\mathrm{UCC}}}, \\
\alpha_{\mathrm{Na}} & =\frac{[\mathrm{Sm} / \mathrm{Na}]_{\text {Sample }}}{[\mathrm{Sm} / \mathrm{Na}]_{\mathrm{UCC}}}, \\
\alpha_{K} & =\frac{[\mathrm{Th} / \mathrm{K}]_{\text {Sample }}}{[\mathrm{Th} / \mathrm{K}]_{\mathrm{UCC}}}
\end{aligned}
$$

$$
\begin{aligned}
& \alpha_{S r}=\frac{[N d / S r]_{\text {Sample }}}{[N d / S r]_{\mathrm{UCC}}}, \\
& \alpha_{B a}=\frac{[T h / B a]_{\text {Sample }}}{[T h / B a]_{\mathrm{UCC}}} .
\end{aligned}
$$

The $\alpha$ ratios could also minimize the effects of quartz dilution, grain size, and recycling. According to the definition of the $\alpha$ value, $\alpha<1$ indicates enrichment and $\alpha>1$ implies depletion with respect to the UCC.

\section{Major and Trace Elements, and the Chemical Weathering Intensity}

The element concentrations are shown in Table 1. Most of the Hainan riverine sediments have Sc/Th values smaller than 1 , while two samples have values higher than 1 on the north Hainan (Figure 3A). The CIA values of all the samples range from 72 to 90 (mean of 81), which indicates moderate to intensive weathering occurred in the Hainan Island. The CIA values exhibit no obvious correlation with $\mathrm{Sc} / \mathrm{Th}$ ratios (Figure 3A). The WIP values of all the samples range from 18 to 52 (mean of 34). The CIA and WIP values of all the samples display an inverse linear relationship (Figure 3B), showing a similar trend with the Taiwan rivers (Selvaraj and Chen, 2006), Pearl, Red, and Mekong (Liu et al., 2007), Malay Peninsula, Sumatra, Borneo (Liu et al., 2012), and Luzon rivers (Liu et al., 2009). As shown in Table 2, the similar values of the CIA at different parts of the Hainan Island suggest the similar weathering degree of Hainan riverine sediments. However, the lower mean WIP value of north Hainan suggests a higher weathering degree.

The weathering indexes, such as $\alpha_{C a}, \alpha_{N a}, \alpha_{K}, \alpha_{S r}$, and $\alpha_{B a}$, are also $>1$ (Table 2). As shown in Figure 3C, a high coefficient correlation can be observed between some indexes indicating that these indexes give relatively consistent information on the weathering degree of Hainan riverine sediments. Overall, the $\alpha_{C a}, \alpha_{K}, \alpha_{S r}$, and $\alpha_{B a}$ values of north Hainan are higher than those of the southwest and east Hainan (Figure 3C). This also suggests the higher weathering degree of the north Hainan Island.

\section{DISCUSSION}

\section{Topographic Control on the Highest Weathering of North Hainan}

The elements Sc and Th are largely water immobile during chemical weathering. Typically, felsic rocks generally have Sc/ Th values smaller than 1 , and mafic rocks have higher $\mathrm{Sc} / \mathrm{Th}$ values (Taylor and McLennan, 1985). Most of the Hainan riverine sediments have $\mathrm{Sc} / \mathrm{Th}$ values smaller than 1 , indicating the dominance of the felsic rocks in the catchment (i.e., granitic rocks and Quaternary sediments). Only two samples have Sc/Th values higher than 1 on the north Hainan, indicating the influence of the mafic rocks in the catchment (i.e., basalt rocks). The CIA values exhibit no obvious correlation with $\mathrm{Sc} / \mathrm{Th}$ ratios (Figure 3A), suggesting that the chemical weathering intensities are mostly independent of the lithology of their source areas. This is consistent with the previous studies on 


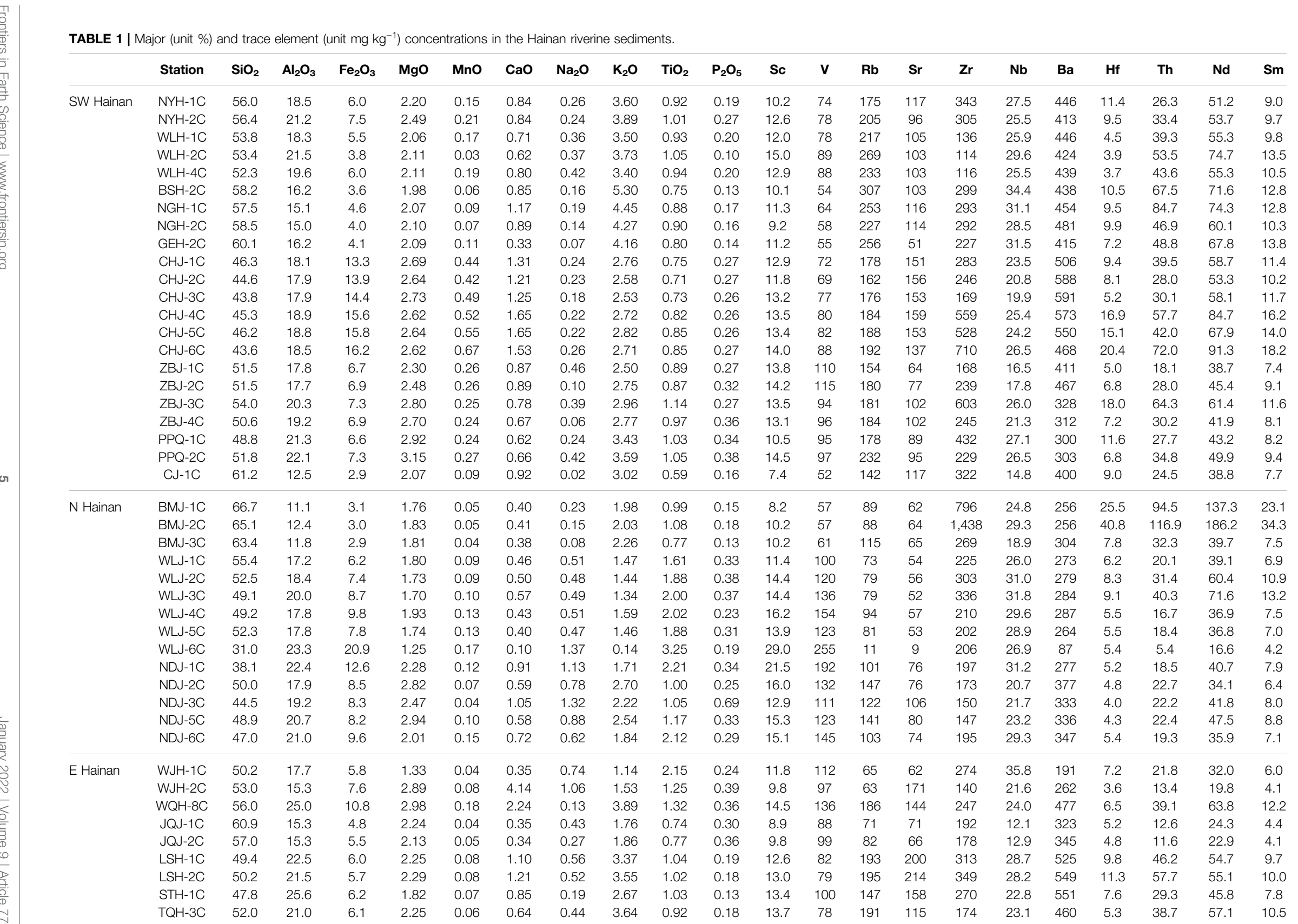




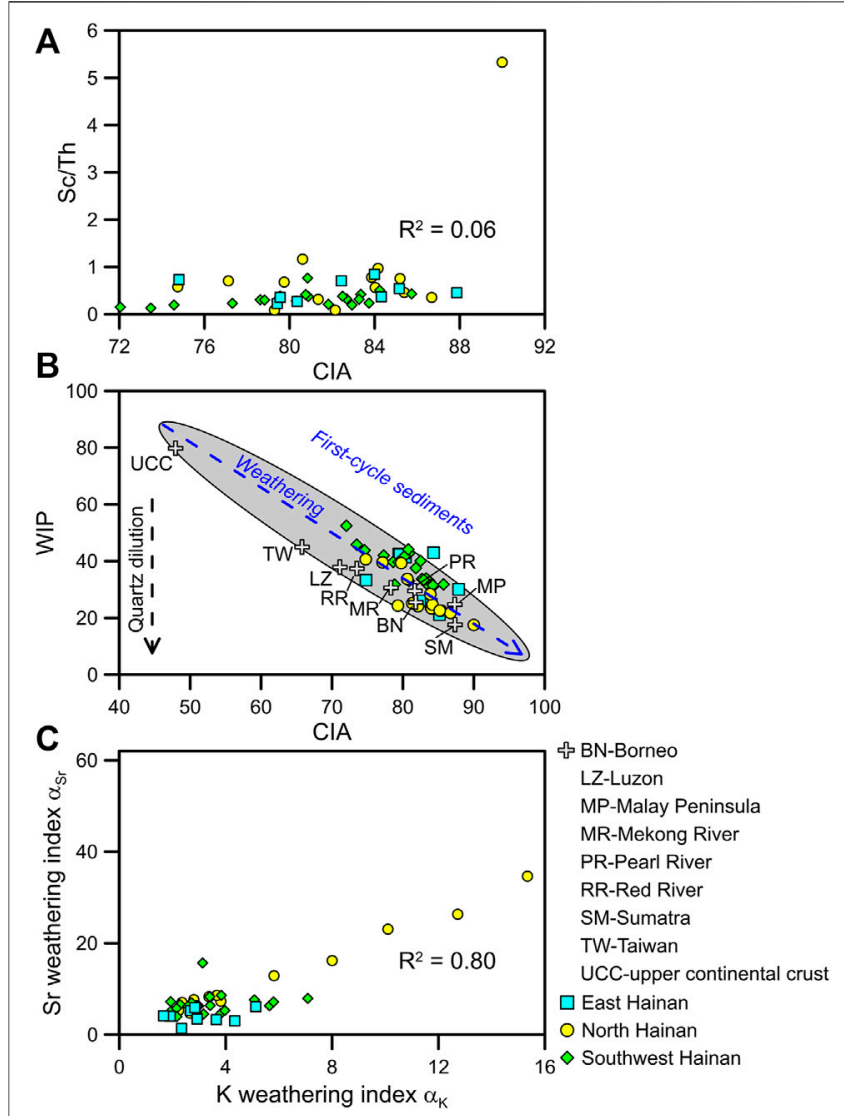

FIGURE 3 | Relationships between (A) CIA and Sc/Th, (B) CIA and WIP, and (C) $\alpha_{K}$ and $\alpha_{S r}$ in riverine sediments of the Hainan Island. The CIA and WIP values of the UCC (Rudnick and Gao, 2003), Taiwan rivers (Selvaraj and Chen, 2006), Pearl, Red, and Mekong (Liu et al., 2007), Malay Peninsula, Sumatra, Borneo (Liu et al., 2012), and Luzon rivers (Liu et al., 2009) are also shown for comparison.

silicate weathering in river basins of mainland China ( $\mathrm{Li}$ and Yang, 2010; Shao et al., 2012; Bi et al., 2015).

The comparison of CIA and WIP indexes could be used to identify the composition changes caused by weathering and recycling. The relationship between CIA and WIP is linear for first-cycle muds as well as for quartz-poor igneous materials (Garzanti et al., 2013; Garzanti et al., 2014; Guo et al., 2018). The inverse linear relationship of the CIA and WIP (Figure 3B) indeed suggests that the Hainan sediments only experienced a first sedimentary cycle, and thus faithfully reflects the present weathering intensity. Thus, the significantly low WIP values of sediments in north Hainan indicate strong chemical weathering intensity in the area.

Alkaline and alkaline earth metals tend to be depleted in riverine sediments due to their mobility during water-rock interactions (Stallard, 1988; Canfield, 1997; Garzanti et al., 2013). The $\alpha_{C a}$, $\alpha_{N a}, \alpha_{K}, \alpha_{S r}$, and $\alpha_{B a}$ values are always $>1$ (Table 2), indicating that most alkali and alkaline elements in parent rocks on the Hainan Island can be easily and intensively weathered under warm and humid climate conditions. As shown in Table 2, the $\alpha_{C a}, \alpha_{K}, \alpha_{S r}$, and $\alpha_{B a}$ values of the north Hainan are much higher than those of the east
TABLE 2 | Proxies for the chemical weathering intensity of the Hainan riverine sediments.

\begin{tabular}{lccccccc}
\hline & CIA & WIP & $\alpha_{\mathbf{C a}}$ & $\alpha_{\mathbf{N a}}$ & $\alpha_{\mathbf{K}}$ & $\alpha_{\mathbf{S r}}$ & $\alpha_{\mathbf{B a}}$ \\
\hline Southwest Hainan & 80.5 & 37.9 & 6.0 & 52.5 & 3.4 & 6.6 & 5.9 \\
North Hainan & 82.5 & 27.7 & 16.1 & 27.9 & 5.6 & 12.4 & 7.5 \\
East Hainan & 82 & 33.8 & 9.9 & 17.9 & 3.1 & 4.1 & 4.3 \\
\hline
\end{tabular}

and southwest Hainan, also indicating higher weathering degree than the latter. As noted above, the vast platforms are mainly distributed in the north Hainan, while the high mountains are located south of the central part of the island. Indeed, the topography could exert an important impact on sediment and its comminution process (Bi et al., 2015; Li C. et al., 2016). Considering that there is no obvious difference in climate conditions between the north and east Hainan (Figure 2), the chemical weathering intensities are also independent of the lithology of their source areas. We suggest that the highest chemical weathering intensities of sediments in north Hainan are mainly influenced by the flat topography under a favorable monsoon climate.

\section{Lower Rainfall Control on Higher Weathering of Southwest Than East Hainan}

The CIA and WIP values of sediments on the southwest and east Hainan Island are similar, indicating the similar weathering degree of the riverine sediments. However, the $\alpha_{N a}, \alpha_{K}, \alpha_{S r}$, and $\alpha_{B a}$ values of southwest Hainan are much higher than those of the east Hainan. These suggest that although the overall weathering degree of the southwest Hainan is comparable with the east Hainan, the leaching of elements such as $\mathrm{Na}, \mathrm{K}, \mathrm{Sr}$, and $\mathrm{Ba}$ is more extreme. This is also supported by the more negative Eu anomalies at the southwest than the east Hainan ( 0.45 and 0.65 , respectively, unpublished data), reflecting stronger feldspar dissolution. The east and southwest Hainan are both located in a tectonically stable area (Metcalfe, 2009). Moreover, the main rock types are the same, that is, granitic rocks (Shi et al., 2011). As noted above, located in the rain shadow because of the orographic effect of the central mountains, the summer rainfall of southwest Hainan is lower than that of east Hainan. In addition, southwest Hainan is rich in light and heat, leading to a large amount of evaporation, while evaporation of the east part is relatively small due to heavy rainfall and the long rain period (Yang et al., 2013). Thus, the physical denudation should be stronger in the east than the southwest Hainan Island. The riverine sediments in southwest Hainan may experience longer residence time and stronger weathering intensity than those in east Hainan. Further studies on the "residence time" (Suresh et al., 2013) or "comminution age" (DePaolo et al., 2006; Li et al., 2015) of sediments from the small mountainous rivers in the southwest and east Hainan are needed to confirm this proposal.

\section{Intensive Weathering of Hainan Compared With the Adjacent Area}

The weathering trend can be further examined by ternary diagrams of $\mathrm{Al}_{2} \mathrm{O}_{3}-\mathrm{CaO}^{*}+\mathrm{Na}_{2} \mathrm{O}-\mathrm{K}_{2} \mathrm{O}(\mathrm{A}-\mathrm{CN}-\mathrm{K})$ (Nesbitt and 


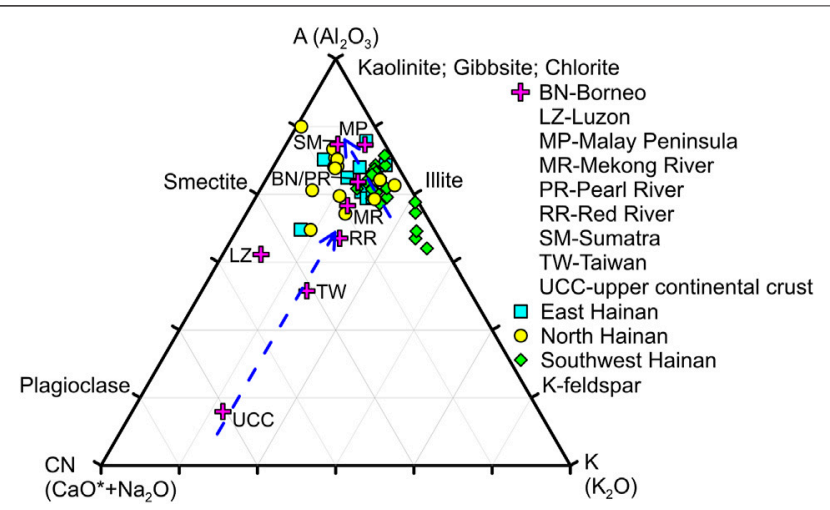

FIGURE 4 | A-CN-K diagram showing the weathering trends of the Hainan riverine sediments. Average data of UCC (Rudnick and Gao, 2003), Luzon (Liu et al., 2009), Taiwan rivers (Selvaraj and Chen, 2006), Red, Mekong, and Pearl (Liu et al., 2007), Borneo (Liu et al., 2012), Sumatra and Malay Peninsula (Liu et al., 2012) rivers are plotted for comparison. Arrows indicate weathering trends exhibited by these sediments.

Young, 1984). Most of the samples of the Hainan Rivers are subparallel to the A-K axis (Figure 4). This reflects the strong removal of K-bearing minerals from the parent rocks, indicating the riverine sediments of the Hainan Island have undergone extensive weathering conditions. The chemical weathering intensity of Hainan Island is higher than that of UCC (Rudnick and Gao, 2003), Luzon (Liu et al., 2009), Taiwan rivers (Selvaraj and Chen, 2006), and Red and Mekong (Liu et al., 2007), and comparable with that of Pearl (Liu et al., 2007) and Borneo rivers (Liu et al., 2012), but less than that of Sumatra and Malay Peninsula rivers (Liu et al., 2012).

Clay minerals in riverine sediments originate mainly from the weathering products of parent rocks, and thus can also provide abundant information about weathering types and intensities. The kaolinite formation strongly depends on intensive hydrolysis under warm and humid climates. Illite and chlorite are mainly formed by weak hydrolysis and/or strong physical erosion of bedrock under relatively cold and dry climates (Chamley, 1989). Thus, the kaolinite/(illite + chlorite) ratios could be used to indicate the weathering types (physical erosion vs chemical weathering) of the sediments. The higher kaolinite/(illite + chlorite) values indicate stronger chemical weathering and weaker physical erosion, and vice versa (Colin et al., 2010; Wan et al., 2010; Alizai et al., 2012; Hu et al., 2014).

As shown in Figure 5, the CIA and kaolinite/(illite + chlorite) show good correlations of the different weathering degrees in the surrounding areas of the SCS. The weathering status of Hainan is comparable with that of the Pearl River in South China, Borneo, and weaker than those of the Malay Peninsula and Sumatra in tropical Southeast Asia. The Malay Peninsula and Sumatra are benefited from stable tectonic settings and tropical climate (Liu et al., 2012), favoring the intensity of chemical weathering with strong hydrolysis. However, the sediments of Taiwan in tropical/ subtropical climate, highland part of the Mekong and Red River drainage basins in a subtropical climate, and even North Borneo in a tropical climate are characterized by strong physical erosion and moderate weathering conditions due to the combined effects of tectonic uplift and abundant monsoon rainfall (Liu et al., 2007; Liu et al., 2008; Liu et al., 2012; Sang et al., 2018). The correlations of CIA with kaolinite/(illite + chlorite) support our previous understandings based on the $\mathrm{A}-\mathrm{CN}-\mathrm{K}$ diagram analysis.

For the first and second largest islands in China, the sediment weathering intensities are different on Taiwan and Hainan Island. We can ascribe this to the tectonically active and stable conditions on the two islands (Selvaraj and Chen, 2006; Metcalfe, 2009). The silicate weathering processes of the small rivers in Taiwan Island are typical weathering-limited regimes because of the steep topographic relief and rapid erosion due to plate collision ( $\mathrm{Bi}$ et al., 2015). The intensive chemical weathering of Hainan suggests that the weathering processes exceed the transportability to remove materials due to the dense vegetation cover (Committee of Vegetation Map of China, 2007) although the heavy rainfall and tropical cyclones can trigger short-term extreme flood events (Zhang et al., 2013). Soils and sediments exposed for long periods could be gradually leached and become strongly depleted in soluble cations (Stallard, 1988; Garzanti et al., 2013). Thus, the weathering processes of the sediments in the Hainan Island are typical transport-limited weathering regimes. This can also be supported by the $\sim 4 \mathrm{Mt} /$ yr riverine sediment load from Hainan (Zhang et al., 2013), which shows a huge difference with Taiwan Island, that is, $384 \mathrm{Mt} / \mathrm{yr}$ (Dadson et al., 2003). Located in a tectonically stable area with

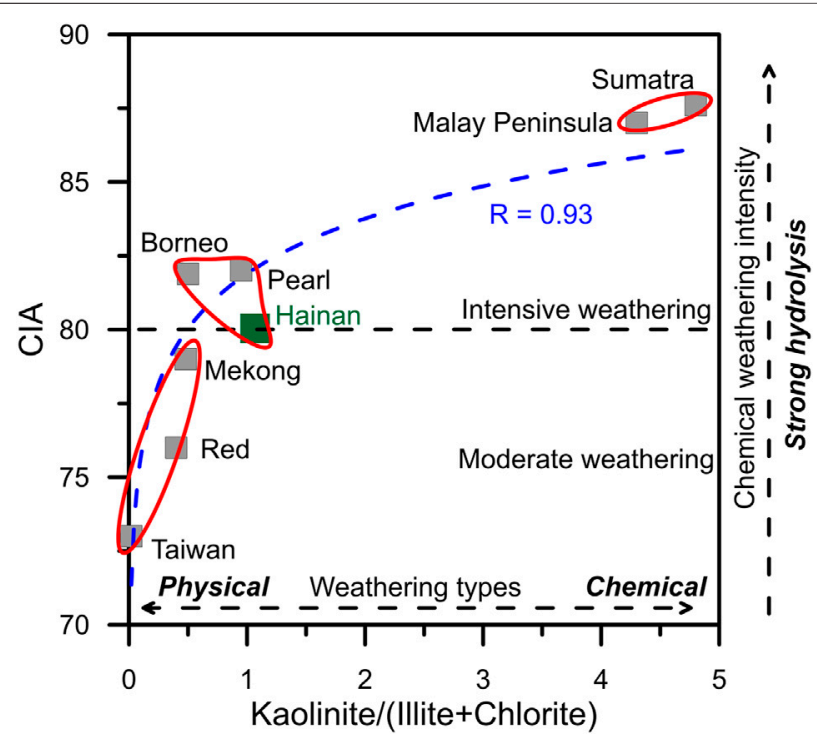

FIGURE 5 | Correlation of CIA with kaolinite/(illite + chlorite) showing the different weathering degrees in the surrounding areas of the SCS. Data of the geochemical elements of Luzon rivers are from the study by Liu et al. (2009), Taiwan rivers from the study by Selvaraj and Chen (2006), the Red, Mekong, and Pearl rivers from the study by Liu et al. (2007), the Malay Peninsula, Sumatra, and Borneo rivers from the study by Liu et al. (2012), and Hainan rivers (this study). Data of the clay minerals of the Luzon rivers are from the study by Liu et al. (2009), the Taiwan rivers from the study by Liu et al. (2008), the Red, Mekong, and Pearl rivers from the study by Liu et al. (2007), the Malay Peninsula, Sumatra, and Borneo rivers from the study by Liu et al. (2012), and Hainan rivers from the study by Hu et al. (2014). 
high temperature and rainfall, the Hainan Island could afford sediments with intensive chemical weathering to the sea.

\section{CONCLUSIONS}

The concentrations of major and trace elements in the Hainan riverine sediments were analyzed. The high CIA, low WIP, and high weathering indexes (such as $\alpha_{C a}, \alpha_{N a}, \alpha_{K}, \alpha_{S r}$, and $\alpha_{B a}$ values) indicate an advanced stage of weathering of Hainan sediments. The similar values of the CIA at different parts of the Hainan Island suggest that there is little difference in weathering products although the parent rocks are different. The low WIP and high $\alpha_{C a}, \alpha_{K}, \alpha_{S r}$, and $\alpha_{B a}$ values of north Hainan indicate the highest weathering degree, which is mainly influenced by the flat topography. The higher $\alpha_{N a}, \alpha_{K}, \alpha_{S r}$, and $\alpha_{B a}$ values of southwest Hainan suggest that although the overall weathering degree of the southwest Hainan is comparable with the east Hainan, the leaching of elements such as $\mathrm{Na}, \mathrm{K}, \mathrm{Sr}$, and $\mathrm{Ba}$ is more extreme. Their main rock types are the same, that is, granitic rocks. The significant difference between the southwest and east Hainan is the low and high summer rainfall. The stronger physical denudation should lead to shorter residence time and lower leaching intensity in the east Hainan than those of the southwest Hainan. Further studies on the "residence time" or "comminution age" of sediments from the small mountainous rivers on the Hainan Island are needed in the future. Compared with the adjacent area, the weathering degree of the Hainan Island is intensive. The weathering status is comparable with that of the Pearl River and Borneo, and relatively weaker than that of the Malay Peninsula and Sumatra due to their stable tectonic settings, and warm and humid climate. The weathering status of Hainan sediments is stronger than those of the Taiwan, Red, and Mekong rivers. Compared to the Taiwan riverine sediments, the weathering processes of the sediments in the Hainan Island are typical transport-limited weathering regimes.

\section{REFERENCES}

Alizai, A., Hillier, S., Clift, P. D., Giosan, L., Hurst, A., VanLaningham, S., et al. (2012). Clay mineral Variations in Holocene Terrestrial Sediments from the Indus Basin. Quaternary Res. 77, 368-381. doi:10.1016/ j.yqres.2012.01.008

Bi, L., Yang, S., Li, C., Guo, Y., Wang, Q., Liu, J. T., et al. (2015). Geochemistry of River-Borne Clays Entering the East China Sea Indicates Two Contrasting Types of Weathering and Sediment Transport Processes. Geochem. Geophys. Geosyst. 16, 3034-3052. doi:10.1002/2015GC005867

Bouchez, J., Gaillardet, J., France-Lanord, C., Maurice, L., and Dutra-Maia, P. (2011). Grain Size Control of River Suspended Sediment Geochemistry: Clues from Amazon River Depth Profiles. Geochem. Geophys. Geosyst. 12, a-n. doi:10.1029/2010GC003380

Canfield, D. E. (1997). The Geochemistry of River Particulates from the continental USA: Major Elements. Geochim. Cosmochim. Ac. 61, 3349-3365. doi:10.1016/ s0016-7037(97)00172-5

Chamley, H. (1989). Clay Sedimentology. Berlin: Springer-Verlag.

Clift, P. D., Wan, S., and Blusztajn, J. (2014). Reconstructing Chemical Weathering, Physical Erosion and Monsoon Intensity since 25Ma in the Northern South China Sea: A Review of Competing Proxies. Earth-Sci. Rev. 130, 86-102. doi:10.1016/j.earscirev.2014.01.002

\section{DATA AVAILABILITY STATEMENT}

The original contributions presented in the study are included in the article/Supplementary Material, further inquiries can be directed to the corresponding author.

\section{AUTHOR CONTRIBUTIONS}

$\mathrm{BH}$ contributed to conceptualization; JZ, RC, and XD performed formal analysis; FX, JZ, XL, GW, and JH contributed to original draft preparation; and $\mathrm{BH}$ and $\mathrm{FX}$ performed review and editing. All authors have read and agreed to the published version of the manuscript.

\section{FUNDING}

This study was jointly supported by the National Natural Science Foundation of China (41976192), the Project of the China Geological Survey (DD20191010), the Shandong Provincial Natural Science Foundation of China (ZR2020MD061 and ZR202103010094), the Open Foundation of the State Key Laboratory of Loess and Quaternary Geology (SKLLQG1707 and SKLLQG 1805), the National Key Research and Development Program of China (2018YFC0310001), and the Independent Project of Hainan Key Laboratory of Marine Geological Resources and Environment (2019256 (2020) HNHSKC-01 and ZZ (2020) 2019256-01).

\section{ACKNOWLEDGMENTS}

We would like to thank the editor, and two reviewers for their constructive comments and reviews of the earlier versions of this study.

Colin, C., Siani, G., Sicre, M.-A., and Liu, Z. (2010). Impact of the East Asian Monsoon Rainfall Changes on the Erosion of the Mekong River basin over the Past 25,000yr. Mar. Geol. 271, 84-92. doi:10.1016/j.margeo.2010.01.013

Committee of Vegetation Map of China (2007). Vegetation Map of the People's Republic of China. Beijing: Geological Publishing House.

Dadson, S. J., Hovius, N., Chen, H., Dade, W. B., Hsieh, M.-L., Willett, S. D., et al. (2003). Links between Erosion, Runoff Variability and Seismicity in the Taiwan Orogen. Nature 426, 648-651. doi:10.1038/nature02150

Deng, K., Yang, S., Bi, L., Chang, Y.-P., Su, N., Frings, P., et al. (2019). Small Dynamic Mountainous Rivers in Taiwan Exhibit Large Sedimentary Geochemical and Provenance Heterogeneity over Multi-Spatial Scales. Earth Planet. Sci. Lett. 505, 96-109. doi:10.1016/j.epsl.2018.10.012

DePaolo, D. J., Maher, K., Christensen, J. N., and McManus, J. (2006). Sediment Transport Time Measured with U-Series Isotopes: Results from ODP North Atlantic Drift Site 984. Earth Planet. Sci. Lett. 248, 394-410. doi:10.1016/ j.epsl.2006.06.004

Dinis, P. A., Garzanti, E., Hahn, A., Vermeesch, P., and Cabral-Pinto, M. (2020). Weathering Indices as Climate Proxies. A Step Forward Based on Congo and SW African River Muds. Earth-Sci. Rev. 201, 103039. doi:10.1016/ j.earscirev.2019.103039

Dupré, B., Gaillardet, J., Rousseau, D., and Allègre, C. J. (1996). Major and Trace Elements of River-Borne Material: The Congo Basin. Geochim. Cosmochim. Ac. 60, 1301-1321. doi:10.1016/0016-7037(96)00043-9 
Egashira, K., Fujii, K., Yamasaki, S., and Virakornphanich, P. (1997). Rare Earth Element and clay Minerals of Paddy Soils from the central Region of the Mekong River, Laos. Geoderma 78, 237-249. doi:10.1016/S0016-7061(97) 00031-1

Gaillardet, J., Dupré, B., and Allègre, C. J. (1999). Geochemistry of Large River Suspended Sediments: Silicate Weathering or Recycling Tracer. Geochim. Cosmochim. Ac. 63, 4037-4051. doi:10.1016/S0016-7037(99)00307-5

Gaillardet, J., Dupre, B., Allegre, C. J., and Négrel, P. (1997). Chemical and Physical Denudation in the Amazon River Basin. Chem. Geol. 142, 141-173. doi:10.1016/S0009-2541(97)00074-0

Garzanti, E., Padoan, M., Setti, M., Najman, Y., Peruta, L., and Villa, I. M. (2013). Weathering Geochemistry and Sr-Nd Fingerprints of Equatorial Upper Nile and Congo Muds. Geochem. Geophys. Geosyst. 14, 292-316. doi:10.1002/ ggge.20060

Garzanti, E., Vermeesch, P., Padoan, M., Resentini, A., Vezzoli, G., and Andò, S. (2014). Provenance of Passive-Margin Sand (Southern Africa). J. Geol. 122, 17-42. doi:10.1086/674803

Guo, Y., Yang, S., Su, N., Li, C., Yin, P., and Wang, Z. (2018). Revisiting the Effects of Hydrodynamic Sorting and Sedimentary Recycling on Chemical Weathering Indices. Geochim. Cosmochim. Ac. 227, 48-63. doi:10.1016/j.gca.2018.02.015

Hu, B., Li, J., Cui, R., Wei, H., Zhao, J., Li, G., et al. (2014). Clay Mineralogy of the Riverine Sediments of Hainan Island, South China Sea: Implications for Weathering and Provenance. J. Asian Earth Sci. 96, 84-92. doi:10.1016/ j.jseaes.2014.08.036

Jian, X., Yang, S., Hong, D., Liang, H., Zhang, S., Fu, H., et al. (2020). Seasonal Geochemical Heterogeneity of Sediments from a Subtropical Mountainous River in SE China. Mar. Geol. 422, 106120. doi:10.1016/j.margeo.2020.106120

Li, C.-S., Shi, X.-F., Kao, S.-J., Liu, Y.-G., Lyu, H.-H., Zou, J.-J., et al. (2013). Rare Earth Elements in fine-grained Sediments of Major Rivers from the HighStanding Island of Taiwan. J. Asian Earth Sci. 69, 39-47. doi:10.1016/ j.jseaes.2013.03.001

Li, C., and Yang, S. (2010). Is Chemical index of Alteration (CIA) a Reliable Proxy for Chemical Weathering in Global Drainage Basins. Am. J. Sci. 310, 111-127. doi:10.2475/02.2010.03

Li, C., Yang, S., Lian, E., Bi, L., and Zhang, Z. (2015). A Review of Comminution Age Method and its Potential Application in the East China Sea to Constrain the Time Scale of Sediment Source-To-Sink Process. J. Ocean Univ. China 14, 399-406. doi:10.1007/s11802-015-2769-8

Li, C., Yang, S., Zhao, J.-x., Dosseto, A., Bi, L., and Clark, T. R. (2016a). The Time Scale of River Sediment Source-To-Sink Processes in East Asia. Chem. Geol. 446, 138-146. doi:10.1016/j.chemgeo.2016.06.012

Li, G., Yan, W., and Zhong, L. (2016b). Element Geochemistry of Offshore Sediments in the Northwestern South China Sea and the Dispersal of Pearl River Sediments. Prog. Oceanogr. 141, 17-29. doi:10.1016/j.pocean.2015.11.005

Liu, Z., Colin, C., Huang, W., Le, K. P., Tong, S., Chen, Z., et al. (2007). Climatic and Tectonic Controls on Weathering in south China and Indochina Peninsula: Clay Mineralogical and Geochemical Investigations from the Pearl, Red, and Mekong Drainage Basins. Geochem. Geophys. Geosyst. 8, a-n. doi:10.1029/ 2006GC001490

Liu, Z., Tuo, S., Colin, C., Liu, J. T., Huang, C.-Y., Selvaraj, K., et al. (2008). Detrital fine-grained Sediment Contribution from Taiwan to the Northern South China Sea and its Relation to Regional Ocean Circulation. Mar. Geol. 255, 149-155. doi:10.1016/j.margeo.2008.08.003

Liu, Z., Wang, H., Hantoro, W. S., Sathiamurthy, E., Colin, C., Zhao, Y., et al. (2012). Climatic and Tectonic Controls on Chemical Weathering in Tropical Southeast Asia (Malay Peninsula, Borneo, and Sumatra). Chem. Geol. 291, 1-12. doi:10.1016/j.chemgeo.2011.11.015

Liu, Z., Zhao, Y., Colin, C., Siringan, F. P., and Wu, Q. (2009). Chemical Weathering in Luzon, Philippines from clay Mineralogy and Major-Element Geochemistry of River Sediments. Appl. Geochem. 24, 2195-2205. doi:10.1016/ j.apgeochem.2009.09.025

Liu, Z., Zhao, Y., Colin, C., Stattegger, K., Wiesner, M. G., Huh, C.-A., et al. (2016). Source-to-sink Transport Processes of Fluvial Sediments in the South China Sea. Earth-Sci. Rev. 153, 238-273. doi:10.1016/j.earscirev.2015.08.005

McLennan, S. M. (1993). Weathering and Global Denudation. J. Geol. 101, 295-303. doi:10.1086/648222

Metcalfe, I. (2009). Late Palaeozoic and Mesozoic Tectonic and Palaeogeographical Evolution of SE Asia. Geol. Soc. London. Spec. Publ. 315, 7-23. doi:10.1144/SP315.2
Milliman, J. D., and Farnsworth, K. L. (2011). River Discharge to the Coastal Ocean - A Global Synthesis. New York: Cambridge University Press.

Milliman, J. D., and Syvitski, J. P. M. (1992). Geomorphic/tectonic Control of Sediment Discharge to the Ocean: the Importance of Small Mountainous Rivers. J. Geol. 100, 525-544. doi:10.1086/629606

Nesbitt, H. W., and Young, G. M. (1982). Early Proterozoic Climates and Plate Motions Inferred from Major Element Chemistry of Lutites. Nature 299, 715-717. doi:10.1038/299715a0

Nesbitt, H. W., and Young, G. M. (1984). Prediction of Some Weathering Trends of Plutonic and Volcanic Rocks Based on Thermodynamic and Kinetic Considerations. Geochim. Cosmochim. Ac. 48, 1523-1534. doi:10.1016/00167037(84)90408-3

Ohta, A., Imai, N., Terashima, S., and Tachibana, Y. (2005). Application of MultiElement Statistical Analysis for Regional Geochemical Mapping in Central Japan. Appl. Geochem. 20, 1017-1037. doi:10.1016/j.apgeochem.2004.12.005

Rudnick, R. L., and Gao, S. (2003). "Composition of the continental Crust," in Treatise on Geochemistry. Editors D. H. Heinrich and K. T. Karl (Oxford (Pergamon), 1-64. doi:10.1016/b0-08-043751-6/03016-4

Sang, P. N., Liu, Z., Zhao, Y., Zhao, X., Pha, P. D., and Long, H. V. (2018). Chemical Weathering in central Vietnam from clay Mineralogy and Major-Element Geochemistry of Sedimentary Rocks and River Sediments. Heliyon 4, e00710. doi:10.1016/j.heliyon.2018.e00710

Selvaraj, K., and Chen, C. T. A. (2006). Moderate Chemical Weathering of Subtropical Taiwan: Constraints from Solid-Phase Geochemistry of Sediments and Sedimentary Rocks. J. Geol. 114, 101-116. doi:10.1086/498102

Shao, J., Yang, S., and Li, C. (2012). Chemical Indices (CIA and WIP) as Proxies for Integrated Chemical Weathering in China: Inferences from Analysis of Fluvial Sediments. Sediment. Geol. 265-266, 110-120. doi:10.1016/j.sedgeo.2012.03.020

Shi, X., Kohn, B., Spencer, S., Guo, X., Li, Y., Yang, X., et al. (2011). Cenozoic Denudation History of Southern Hainan Island, South China Sea: Constraints from Low Temperature Thermochronology. Tectonophysics 504, 100-115. doi:10.1016/j.tecto.2011.03.007

Stallard, R. F. (1988). "Weathering and Erosion in the Humid Tropics," in Physical and Chemical Weathering in Geochemical Cycles. Editors A. Lerman and M. Meybeck (Dordrecht, Kluwer), 225-246. doi:10.1007/978-94-0093071-1_11

Su, N., Yang, S., Guo, Y., Yue, W., Wang, X., Yin, P., et al. (2017). Revisit of Rare Earth Element Fractionation during Chemical Weathering and River Sediment Transport. Geochem. Geophys. Geosyst. 18, 935-955. doi:10.1002/ 2016GC006659

Suresh, P. O., Dosseto, A., Hesse, P. P., and Handley, H. K. (2013). Soil Formation Rates Determined from Uranium-Series Isotope Disequilibria in Soil Profiles from the southeastern Australian highlands. Earth Planet. Sci. Lett. 379, 26-37. doi:10.1016/j.epsl.2013.08.004

Taylor, S. R., and McLennan, S. M. (1985). The Continental Crust: Its Composition and Evolution. Oxford: Blackwell Scientific Publications.

Wan, S., Li, A., Clift, P. D., Wu, S., Xu, K., and Li, T. (2010). Increased Contribution of Terrigenous Supply from Taiwan to the Northern South China Sea since 3Ma. Mar. Geol. 278, 115-121. doi:10.1016/j.margeo.2010.09.008

Xu, F., Hu, B., Zhao, J., Liu, X., Xu, K., Xiong, Z., et al. (2021). Provenance and Weathering of Sediments in the Deep basin of the Northern South China Sea during the Last 38 Kyr. Mar. Geol. 440, 106602. doi:10.1016/ j.margeo.2021.106602

Xu, Z., Lim, D., Choi, J., Yang, S., and Jung, H. (2009). Rare Earth Elements in Bottom Sediments of Major Rivers Around the Yellow Sea: Implications for Sediment Provenance. Geo-Mar. Lett. 29, 291-300. doi:10.1007/s00367-009$0142-\mathrm{x}$

Yang, S., Jung, H.-S., and Li, C. (2004). Two Unique Weathering Regimes in the Changiang and Huanghe Drainage Basins: Geochemical Evidence from River Sediments. Sediment. Geol. 164, 19-34. doi:10.1016/ j.sedgeo.2003.08.001

Yang, S., and Yin, P. (2018). Sediment Source-To-Sink Processes of Small Mountainous Rivers under the Impacts of Natural Environmental Changes and Human Activities. Mar. Geol. Quat. Geol. 38, 1-10. (in Chinese with English abstract).

Yang, S. Y., Jung, H. S., Choi, M. S., and Li, C. X. (2002). The Rare Earth Element Compositions of the Changiiang (Yangtze) and Huanghe (Yellow) River Sediments. Earth Planet. Sci. Lett. 201, 407-419. doi:10.1016/S0012-821X(02)00715-X 
Yang, Z. H., Jia, J. J., Wang, X. K., and Gao, J. H. (2013). Characteristics and Variations of Water and Sediment Fluxes into the Sea of the Top three rivers of Hainan in Recent 50 Years. Mar. Sci. Bull. 32, 92-99. (in Chinese with English abstract).

Zhang, J., Wang, D. R., Jennerjahn, T., and Dsikowitzky, L. (2013). Land-sea Interactions at the East Coast of Hainan Island, South China Sea: A Synthesis. Cont. Shelf Res. 57, 132-142. doi:10.1016/j.csr.2013.01.004

Zhou, X., Li, A., Jiang, F., and Meng, Q. (2010). A Preliminary Study on Fingerprinting Approach in marine Sediment Dynamics with the Rare Earth Elements. Acta Oceanol. Sin. 29, 62-77. doi:10.1007/s13131-010-0051-x

Conflict of Interest: The authors declare that the research was conducted in the absence of any commercial or financial relationships that could be construed as a potential conflict of interest.
Publisher's Note: All claims expressed in this article are solely those of the authors and do not necessarily represent those of their affiliated organizations, or those of the publisher, the editors, and the reviewers. Any product that may be evaluated in this article, or claim that may be made by its manufacturer, is not guaranteed or endorsed by the publisher.

Copyright ( $) 2022 \mathrm{Xu}, \mathrm{Hu}$, Zhao, Liu, Cui, Ding, Wang and Huang. This is an openaccess article distributed under the terms of the Creative Commons Attribution License (CC BY). The use, distribution or reproduction in other forums is permitted, provided the original author(s) and the copyright owner(s) are credited and that the original publication in this journal is cited, in accordance with accepted academic practice. No use, distribution or reproduction is permitted which does not comply with these terms. 